\title{
Fundamentos metodológicos de los territorios discursivos
}

\section{Methodological foundations of discursive territories}

Sandra Villanueva-Gallardo (svillanuevagallardo@gmail.com) Centro de Estudios del Desarrollo Regional y Políticas Públicas, Universidad de Los Lagos (Osorno, Chile) ORCID: 0000-0001-5594-7216

\begin{abstract}
Discursive territories are created through the conformation of two dimensions, one that attends to its discursive components and the other that responds to the territorial characteristics where everything unveiled through discourse is constituted in a territorial-identity hologram. This means that we are facing a type of territory traditionally rendered invisible, in large part, by the subalternization of discourses and the recusal of territories. Therefore, this research aims to account for the components that make discursive territories a territorial reality with recognizable meanings, both in its symbolic and material aspects, from an epistemological origin that attends to the nature of the phenomenon.
\end{abstract}

Key words: hologram, affectivity, territoriality, imaginary, coloniality, power.

\section{Resumen}

Los territorios discursivos se erigen mediante la conformación de dos dimensiones, una que atiende a sus componentes discursivos y la otra que responde a las características territoriales donde todo lo develado por medio del discurso se constituye en un holograma territorial-identitario. Esto significa que nos encontramos frente a un tipo de territorio tradicionalmente invisibilizado, en gran parte, por la subalternización de los discursos y la no consideración recursiva de los territorios. Por tanto, esta investigación pretende dar cuenta de los componentes que hacen de los territorios discursivos una realidad territorial con sentidos reconocibles, tanto en sus aspectos simbólicos como materiales, desde un origen epistemológico que atiende a la naturaleza del fenómeno.

Palabras clave: holograma, afectividad, territorialidad, imaginario, colonialidad, poder.

\section{Introducción}

Las concepciones epistemológicas sobre territorio indagan en torno a variadas aristas, algunas de ellas opuestas y otras complementarias. La geografía física, por ejemplo, es una rama de la ciencia que identifica al territorio por sus características materiales y medibles, en cambio la geografía humana lo vincula tanto a aspectos físicos como inmateriales, sumando al espacio habitado las nociones de identidad y territorialidad. En este entendido, podemos afirmar que el concepto territorio ha realizado un recorrido que actualmente se ancla en una combinación de elementos tangibles e intangibles, siendo recomendable la conjunción de ambos aspectos, para su real comprensión y elucidación. 
Por un camino distinto, encontramos los fundamentos teóricos epistemológicos que dan cuerpo a nuestra investigación en lo que hemos denominado territorios discursivos, concepto que abordamos desde las orientaciones de las epistemologías del sur de B. de Sousa Santos. Esta propuesta tiene una localización teórica que se relaciona con las ideas desarrolladas por la corriente decolonial, más específicamente con las nociones de pensamiento fronterizo de G. Anzaldúa, donde la frontera es traducida como un espacio de rebeldía ante las negaciones modernas-coloniales, de rechazo ante la subordinación de los cuerpos racializados e invisivilización de conocimientos, situación que, en nuestro caso, atañe a la limitación del territorio como categoría analítica y restricción sobre las concepciones imaginarias acerca de los espacios y lugares que habitamos los seres humanos. Del mismo modo actúa la colonialidad del saber planteada por E. Lander, donde se expone que las epistemologías y conocimientos otros también han sido colonizados y negados frente a la imposición hegemónica occidental, siendo éste una de las orientaciones principales para trazar nuestro enfoque.

\section{Metodología}

Para efectos de los objetivos planteados por este artículo realizaremos los siguientes pasos: 1) definiremos operacionalmente el concepto de territorios discursivos (TDs), 2) estableceremos los fundamentos metodológicos que dan forma a los TDs e 3) indagaremos en las implicancias del poder y la frontera discursiva presentes en estos territorios.

Este escenario se vincula con lo que designaremos como el territorio conocido, cuyo referente es la categoría analítica de territorio y las concepciones territoriales validadas hasta hoy por las investigaciones occidentales. En este contexto, nuestro planteamiento está abocado a dar cuenta de un territorio que proviene de una naturaleza territorial distinta, con un origen que se manifiesta recursivamente y que se encuentra asentado en el discurso. En consecuencia, nos encontramos frente a un territorio que existe en el discurso territorial y que a su vez ese discurso territorial existe porque hay un TD que lo estructura, lo norma y le da un sentido. Los ocho fundamentos teóricos epistemológicos de los TDs delimitados dan cuenta de la emergencia de estos territorios, no obstante, es preciso indicar qué son y cómo están constituidos, siendo este el objetivo que nos proponemos desarrollar a continuación.

\section{Definición operacional de territorios discursivos}

En virtud de lo anterior, proponemos pensar a los territorios discursivos como realidades imaginarias, aunque no ficticias, latentes en los discursos territoriales de los sujetos sociales y que, esencialmente, se manifiestan en hologramas que contienen sentidos de identidad territorial. Al comprender los TDs como realidades imaginarias, estamos señalando, por una parte, que son reales para los sujetos colectivos que se identifican con un territorio específico y, por otra parte, que el ámbito en que estas realidades se materializan no es del orden de lo tangible, ni de lo conceptual, sino del mundo de lo imaginario en tanto constitutivo de la condición humana. Por ello, los TDs se encuentran en permanente construcción por sujetos sociales, al tiempo que éstos son, sociohistóricamente, construidos por ellos. Es claro que esta coconstrucción sociohistórica se realiza, la mayoría de las veces, de manera no consciente, por lo que tampoco opera conscientemente en su discursividad.

En tales perspectivas, definimos los TDs como un holograma territorial identitario porque opera como una imagen con significancia social, la que se encuentra en permanente movimiento y puede ser captada mediante la interpretación de los sentidos afectivos que son expresados en los discursos territoriales. De esta manera, actúa metafóricamente como brújula inmersa en los discursos, entregándole a los sujetos 
orientaciones y significados específicos respecto de los lugares a los que refieren. Con otras palabras, corresponde a la ruta que demarcan los TDs para su elucidación, siendo este camino de características territoriales, porque tienen relación con un espacio del cual hay una noción de apropiación o territorialidad, es decir, se expresa como un territorio. Sin embargo, éste no es cualquier espacio físico del cual se ejerce cierta soberanía, sino que es un lugar entendido como "su territorio", en consecuencia, lo que se devela son particularidades identitarias que conforman a los sujetos sociales como pertenecientes a un lugar específico.

Este holograma territorial es distinto al elaborado por el pensamiento eurocéntrico, principalmente porque su propuesta señala a un territorio que no puede ser pensado al margen del discurso, debido a que en rigor se constituye en/con el discurso, aun cuando no es creado por éste. Con otras palabras, solo pueden manifestarse discursivamente. En ellos, en cuanto territorios, podemos encontrar análogos de paisajes, de memorias, de tiempos y espacios, así como de otros factores de identidad territorial: límites y fronteras, sentidos del poder, los cuales actúan también discursivamente. Esto se logra evidenciar por medio de lo que denominaremos puntos de fuga en los discursos, traducidos como aspectos afectivos plasmados en alguna instancia a través del relato oral, escrito o icónico, como el caso de las imágenes y sus simbolismos.

Consideramos que tal discursividad puede desplegarse en una interpretación hermenéutica, ya que, al margen de la acción interpretativa, los TDs permanecen ocultos, aunque activos en la configuración (preconsciente) de los discursos territoriales. Así, requeriremos de una hermenéutica de los territorios discursivos que dé cuenta de dichos aspectos invisibilizados, por omisión o represión, en los discursos territoriales sean, por ejemplo, emociones o sentimientos ligados a deseos, o re-sentimientos vinculados a frustraciones, o bien, relaciones de poder reprimidas o desconocidas, además de fronteras territoriales identitarias sentidas como propias o como usurpadas, características que pueden coincidir o contradecir relatos hegemónicos sobre un territorio en particular. Dichos aspectos serán rastreados a través de tres características principales que se convertirán en criterios metodológicos: (1) memoria colectiva, traducida a elementos discursivos que contengan aspectos recurrentes y de alta carga significativa respecto del territorio, (2) puntos de fuga, entendidos como marcas afectivas (nostalgia, amor, desprecio, indiferencia, odio, etc. que indiquen conexión sobre un determinado lugar y (3) mapas mentales del territorio, imágenes que sean plasmadas por los sujetos que definen a un territorio en particular.

De esta forma, el primer paso, es posicionarse desde una naturaleza territorial diferente, pero sin perder de vista que, aunque sean otros los contenidos que se le otorgan a las categorías utilizadas, seguimos hablando de territorios que tienen formas, movimientos, paisajes e identidades.

\section{Fundamentos metodológicos de los territorios discursivos}

Los TDs resultan como proyecciones hologramáticas que se revelan en la discursividad de los sujetos sociales, siendo posibles de rastrear mediante la interpretación hermenéutica de los discursos.

Para materializar metodológicamente esta idea, emplearemos varios de los recursos conceptuales del territorio conocido, con la diferencia que estarán aplicados desde la naturaleza de nuestra propuesta. El objetivo de aquello es dar cuenta acerca de la dimensión territorial que componen a los TDs e identificar los aspectos en los que se sitúa su interpretación. Nos referimos a cinco características que funcionan como claves metodológicas que al ser comparadas con las dimensiones que tradicionalmente se atribuyen 
a los territorios, se logra concebir la forma que adquieren. Aludimos específicamente al 1) espacio físico, 2) territorialidad, 3) memoria, 4) tiempo y 5) paisaje.

El espacio físico de los TDs se encuentra en los discursos territoriales, actuando como el lugar específico en que habitan sus significaciones. Esta primera dimensión es la puerta de entrada a la configuración del holograma territorial, sin embargo, no es suficiente para llegar a elucidarlo, debido a que los discursos se expresan como el mapa que demarca el camino, constituyendo el cuerpo físico interpretable para aunar las características diseminadas en la colectividad, sin embargo, el espacio concreto determinado por los discursos territoriales pueden ser de variadas formas y adquirir distintos matices al estar expresados por medio de la oralidad, la escritura y/o la iconografía. Por ende, se requiere de una intersección metodológica que vislumbre el sentido identitario y configure el holograma territorial correspondiente al contexto sociocultural en el cual se produce.

La intersección analítica que proponemos de base consiste en dos etapas. La primera radica en la interpretación hermenéutica de los discursos territoriales con el fin de identificar el sentido de identidad presente en estos discursos. Este proceso lo pensamos por medio de la hermenéutica diatópica de B. de Sousa Santos, estableciendo los lugares comunes o enunciados basales de cada cuerpo discursivo. Esta interpretación se realiza mediante un trabajo de co-labor donde los análisis son desarrollados en conjunto con los sujetos de conocimiento pertenecientes a las colectividades consultadas.

Una segunda etapa consiste en colocar bajo la óptica analítica de los hologramas espaciales de A. Lindón, el sentido de identidad interpretado en los distintos registros discursivos (orales, escritos e iconográficos) con la finalidad de interpretar las imágenes contenidas y de esta manera configurar el holograma territorial inmerso en los discursos, dando origen a los TDs.

La territorialidad está referida a "Ios fenómenos del arraigo, del apego y del sentimiento de pertenencia socioterritorial" (Giménez 2001:6). Nos habla del proceso afectivo mediante el cual nos apropiamos del espacio y lo incluimos como un aspecto conformante de la identidad.

El sentido profundo de lo expuesto está asentado en la existencia de una relación de apropiación más allá de los aspectos físicos que involucran un habitar entre personas y un lugar determinado. Esta relación de afectividad, que puede perdurar por años en los sujetos, que además es transmisible por individuos de una misma comunidad, es lo que denominamos territorialidad, como la característica más próxima al territorio.

Este elemento está presente en los TDs por medio de la relación entre memoria y afectividad, pues es a través de los recuerdos, las experiencias vividas, los imaginarios, que las personas configuran las imágenes compartidas y develadas hermenéuticamente como realidades hologramáticas. Por tanto, planteamos la presencia de una territorialidad discursiva experimentada con un sentido de identidad y expresada en las convicciones sobre el territorio más allá de las fronteras físicas reconocidas por la traducción occidental.

Situamos el foco de atención en la afectividad, porque la territorialidad discursiva emerge a través del sentido provocado por conexiones identitarias evocadas por la memoria colectiva, todo lo cual se expresa a través del discurso. En palabras de Duarte y Berríos "no se trata de ver en las emociones un distractor del mundo social, por el contrario, la idea es hacer visibles y explícitos los vínculos entre afectividad e interacción social para entender mejor cómo funcionan las relaciones coloniales" (Duarte y Berrío 2018:118). 
La memoria actúa como medio para acceder al sentido de identidad que se plasma discursivamente. A través de la memoria estos discursos adquieren profundidad en el significado que se les otorga a las palabras, ya sean habladas, escritas o icónicas, pudiendo ser una memoria de un pasado imaginado, de un pasado vivido o bien de una experiencia reciente que se conecta con la memoria colectiva.

Para el caso de TDs que refieren a instituciones, como el Estado, es la historia contada a través de textos y discursos oficiales. Su fuente de sentidos y experiencias, no obstante, aluden al mismo principio de tiempo rememorado y validado territorialmente que es posible de ser contrastado con los discursos emitidos por los sujetos pertenecientes a un grupo determinado.

El pasado presentificado o el revivir el pasado como acontecimiento cotidiano del presente, es una posibilidad recurrente para los TDs en una unión significativa entre recuerdos, sentimientos y vivencias. Por ende, el discurso territorial actúa como expresión de la memoria, sin embargo, es preciso el empleo de recursos que gatillen estos recuerdos, pues no necesariamente son elementos que surgen de forma espontánea. Por lo anterior, la memoria en los TDs actúa como categoría de análisis y herramienta metodológica al mismo tiempo.

Para el logro de este objetivo, sugerimos el tratamiento horizontal de todos los aspectos que involucren a sujetos de conocimientos en lo que se denomina investigación de co-labor, donde la hermenéutica diatópica sea el instrumento de interpretación de los discursos.

El tiempo otorga particularidades históricas a los TDs, pues éstos responden a las características de su época y cambian de acuerdo con los contextos en los cuales se producen. De esta manera, los TDs actuales de una colectividad determinada, presentan un tipo de territorio que no necesariamente coincidirá con el mismo grupo que se expresa en un contexto sociohistórico distinto.

Los diferentes tiempos que operan en los TDs se presentan por medio de marcas textuales, palabras claves, relatos situados que evidencian temporalidades vividas en los discursos, siendo el tiempo occidental-lineal una de las posibilidades, mas no la única ni necesariamente la principal que le da forma a estos territorios. Esto se evidencia, sobre todo, si consideramos a las cosmologías indígenas como un colectivo efectivo de representación de los TDs por representar íntegramente la negación e invisivilización de maneras otras de vivir y habitar los territorios.

El paisaje es la imagen en forma de holograma que es posible de recuperar a través de la memoria y los discursos, no obstante, no es una fotografía del territorio, sino una imagen en movimiento que da cuenta de las particularidades sociohistóricas de la época y de los individuos que comparten un mismo territorio discursivo. Es fragmento de la dimensión imaginaria que se configura con los elementos territoriales dispersos en los discursos, resultando un elemento tangible de la elucidación hermenéutica de éstos.

En el paisaje se expresan implícitamente aspectos temporales de los TDs, como por ejemplo la época a la cual pertenecen los lugares señalados o los bordes fronterizos que los conforman, los que pueden ser interpretados y traídos a presencia mediante la identificación de los lugares comunes en los discursos. Sin embargo, también es preciso reconocer aspectos que adquieren distintas connotaciones con respecto a los territorios. Nos referimos específicamente a que pudieran señalar una descripción territorial que tiene directa relación con el lugar físico aludido, respetando las fronteras validadas por la colectividad o bien, por otra parte, pudieran ser una concepción territorial totalmente diferente. 
Una explicación que podemos ofrecer en este punto es que los TDs son construcciones imaginarias plurales y heterogéneas, donde la hegemonía de un TDs por sobre otro subalterno hace visible las características del dominante, pero no por ello invisibiliza por completo la existencia de los otros que están operando en diversos tipos de discursos. Por ejemplo, en el caso del Estado chileno, pudieran encontrarse TDs que no estén en plena concordancia con el texto institucional y que probablemente comprendan ciertos espacios de conflicto (como es el caso del territorio mapuche) de una forma distinta a lo que hoy se señala como realidad.

\section{Territorios discursivos: relación con el poder y el afecto}

Otro de los aspectos significativos desde los estudios occidentales del territorio, es lo vinculado a las relaciones de poder que en un lugar se llevan cabo. Esto nos lleva a entender que para que los TDs emerjan, se tienden a producir modificaciones en dichas relaciones, visibilizando las marcas discursivas que permiten su elucidación.

Este cambio relacional puede ser sutil, donde los sujetos expresan sus expectativas reales sobre sus territorios de acuerdo con su memoria colectiva y conformación identitaria, donde existe un alto grado de coherencia entre la realidad imaginaria y el espacio físico aludido. Pero también es posible una segunda alternativa, consistente en modificaciones que apuntan a un ámbito más radical, reclamando lo que se conoce como justicia territorial, es decir, la demanda explícita a la pregunta sobre "cómo involucrar las diferencias -de clase, género, raza y etnia- en la búsqueda de la justicia y de geografías alternativas más justas en aquellos contextos totalmente injustos y opresivos" (Santana Rivas 2012:83).

Aunque estas son dos potencialidades de las relaciones de poder en los TDs, existe un aspecto metodológico primordial que involucra la interpretación de los discursos territoriales. Por una parte, el poder en los territorios discursivos se encuentra catalizado por los afectos y la afectividad en los TDs, que corresponde a uno de aspectos claves o lugares comunes de la hermenéutica que empleamos. Esto significa que las emociones territoriales (sean expresiones de apego o desapego), actúan en el marco de los TDs como apertura a las expectativas sobre el territorio, donde se exponen las convicciones sobre el espacio habitado, revelándose como puntos de fuga que muestran significaciones espacios-temporales.

Esta fuerza discursiva desplegada mediante la afección o desafección territorial es uno de los puntos de inflexión que metodológicamente buscamos para dar cuenta de la realidad hologramática de los TDs. En este contexto, no hay que perder de vista las diversas manifestaciones afectivas que son expresiones de la diversidad cultural, donde lo que simboliza una emoción para un grupo humano puede ser diametralmente distinto en otro. Por ello, el análisis de co-labor hermenéutico con sujetos de conocimiento pertenecientes a las distintas culturas es una posición ética abordada desde el inicio de nuestros planteamientos.

La expresión de las marcas afectivas en los discursos territoriales puede señalar potencialidades hegemónicas o contra hegemónicas según sea el caso. Desde esta perspectiva se podría creer que los TDs aluden mayoritariamente solo a espacios que demandan justicia territorial, sin embargo, los afectos y sus respectivas relaciones con el poder pueden ser ajenos a la búsqueda de equidad socio-territorial por ser reflejo de realidades imaginarias diversas.

De esta forma, para que surjan los TDs se requiere de la apertura de las expresiones otras sobre los territorios, aquellas que hablan subrepticiamente desde las emociones y que se plasman tácitamente en 
los discursos. Esto significa que los TDs norman y dan un sentido identitario a los discursos territoriales, entregando orientaciones específicas sobre los lugares a los que refieren, no obstante, la mayoría de las veces operan de manera no premeditada en la discursividad.

\section{La frontera discursiva}

La delimitación espacial de los territorios discursivos se expresa como umbrales fronterizos que no compiten con otros bordes, centrándose en la identidad propia del sujeto territorial, sin localizar de forma relevante al otro, sino como manifestación tangible que convierten al espacio vivido y a la memoria colectiva en los límites físicos del territorio.

Ello implica que la fuerza afectiva del discurso tiene relación con las características del lugar identitario y no con otros espacios o lugares que materialmente (en un mapa, por ejemplo) podríamos relacionar. Aunque se manifiesten discursivamente la existencia de otros lugares, en su conformación hologramática están expresados como un solo territorio. En consecuencia, la frontera es un borde que demarca a los TDs por medio de las vivencias, recuerdos o imaginarios conectados con elementos identitarios. Por tanto, la configuración del holograma territorial resulta una proyección acotada a la identidad de los sujetos, donde los bordes fronterizos son la territorialidad desplegada desde sus imaginarios hacia la apropiación simbólica, cuyos verdaderos alcances son actualmente desconocidos.

\section{Consideraciones finales}

De esta manera, los aspectos conceptuales que se reconocen como integrantes de un territorio son posibles de decodificar en los TDs, no obstante, adquieren una especificidad distinta que podemos sintetizar de la siguiente forma:

1. Los territorios discursivos norman, estructuran y dan sentido a los discursos territoriales.

2. Todo discurso territorial remite a un tipo de territorio discursivo, el cual se proyecta como realidad hologramática.

3. Los TDs son una construcción social desplegada en los discursos territoriales individuales que comparten o representan a determinada colectividad.

4. Los TDs son heterogéneos, pudiendo existir distintos tipos en una misma colectividad discursiva e identitaria.

5. Los TDs responden a circunstancias concretas de producción de los discursos, por ende, éstos van cambiando de acuerdo con los contextos en que se originan.

6. Las relaciones de poder inmersas en los TDs ofrecen distintas posibilidades hegemónicas y contra hegemónicas que pueden coincidir o no con el territorio conocido, dependiendo de los conflictos territoriales que estén expuestos en el contexto sociohistórico específico.

7. La relación existente entre los TDs y la afectividad es un aspecto clave para su elucidación metodológica.

8. La estrategia hermenéutica que proponemos para su develación consiste en dos etapas marcadas por la hermenéutica diatópica y los hologramas espaciales.

9. Los TDs emergen sobre una territorialidad discursiva de características culturales y simbólicas, donde los aspectos inmateriales son elementos que le dan forma al territorio.

10. La frontera de los TDs está determinada por la identidad de los sujetos sociales. 
Para finalizar, una de las lógicas principales que conforman a los TDs es la inversión en la relevancia de los aspectos simbólicos frente a los elementos materiales o físicos del territorio. En los TDs las particularidades inmateriales priman ante lo tangible, estando sus fundamentos arraigados en las identidades, lo hologramático, la memoria, lo imaginario, lo discursivo y lo colectivo.

La pregunta que surge a partir de lo anterior es por qué sería importante revelar estas relaciones de poder con los territorios, si corresponden al ámbito de las emociones y lo imaginario. Podemos responder, porque son territorios que son y existen, tienen relevancia por el hecho de ser y estar como expresión territorial invisibilizada por la visión hegemónica occidental. En segunda instancia, debido a que guardan relación con la comprensión de los territorios sometidos a lógicas modernas-capitalistas, porque se refieren a ellos y los incluyen en alguna parte del holograma territorial, es decir, no están ajenos a los espacios físicos delimitados materialmente y a las construcciones territoriales consideradas como reales. En este sentido, la comprensión sobre cómo se erigen y qué dicen los TDs puede resultar un aporte en el diálogo entre culturas y una alternativa para cuestionar la hegemonía de la constitución jurídica de los territorios, pues por medio de éstos podemos llegar a entender aspectos no considerados, pero reales, sobre el habitar de los seres humanos y la apropiación territorial que se manifiesta.

\section{Agradecimientos}

Este artículo es parte del proyecto de la Universidad de Los Lagos FNI/03/2017 “Fundamentos teóricos metodológicos de los territorios discursivos para el estudio de la poesía mapuche del sur de Chile y de los discursos territoriales del Estado, a comienzos del siglo XXI" y del financiamiento de Becas CONICYT.

\section{Bibliografía}

Duarte, A y Berrío, L. 2018. Saberes en diálogo: mujeres indígenas y académicas en la construcción del conocimiento, pp. 107-132. En: Leyva, X. [et al.]. Prácticas otras de conocimiento(s). Entre crisis, entre guerras. Buenos Aires: CLACSO. http://biblioteca.clacso.edu.ar/clacso/se/20180515110853/Practicas Otras 2.pdf

Giménez, G. 2001. Cultura, territorio y migraciones. Aproximaciones teóricas. Alteridades 11(22): 5-14. https://alteridades.izt.uam.mx/index.php/Alte/article/view/381/380

Santana Rivas, D. 2012. Explorando algunas trayectorias recientes de la justicia en la geografía humana contemporánea: de la justicia territorial a las justicias espaciales. Cuadernos de Geografía: Revista Colombiana de Geografía 21(2): 75-84. https://doi.org/10.15446/rcdg.v21n2.32214

Recibido el 22 Mar 2018

Aceptado el 16 Jun 2018 